\title{
Viscoelastic behaviour of green wood across the grain. Part II. A temperature dependent constitutive model defined by inverse method
}

\author{
Joëlle PASSARD, Patrick PERRÉ* \\ Laboratory of Wood Science (LERMAB), UMR 1093 INRA/ENGREF/Université H. Poincaré Nancy 1, ENGREF, \\ 14 rue Girardet, 54042 Nancy Cedex, France
}

(Received 31 July 2004; accepted 31 May 2005)

\begin{abstract}
This paper proposes a new inverse method to identify Kelvin's elements simultaneously from several creep tests carried out at different temperature levels. The dimensionless formulation derived for this approach allows thermally activated Kelvin's elements to be used on non-isothermal tests. For each studied species and each material direction, four different tests are analysed simultaneously to define the parameters of the constitutive model. Each test comprises a linear increase in temperature, a plateau at the desired temperature $\left(65{ }^{\circ} \mathrm{C}, 85^{\circ} \mathrm{C}\right.$, $105^{\circ} \mathrm{C}$ and $120^{\circ} \mathrm{C}$ respectively) and a final cooling period. The paper ends up with a comprehensive viscoelastic characterisation of oak and spruce in radial and tangential directions, over a temperature range spreading from $40{ }^{\circ} \mathrm{C}$ to $120^{\circ} \mathrm{C}$. Five Kelvin's elements were required for spruce and four elements for oak. Such models are intended to be used in the simulation of wood processing operations, such as drying, steaming, thermal treatment...
\end{abstract}

wood / viscoelastic / Kelvin's element / thermal activation / constitutive model / inverse method

Résumé - Comportement viscoélastique du bois vert dans le plan transverse. Partie II : un modèle de comportement dépendant de la température défini par méthode inverse. Cet article propose une nouvelle méthode inverse capable d'identifier des éléments de Kelvin en analysant simultanément plusieurs essais de fluage. Chaque test comporte trois phases : une montée linéaire en température, un palier à la température voulue $\left(65^{\circ} \mathrm{C}, 85^{\circ} \mathrm{C}, 105^{\circ} \mathrm{C}\right.$ et $120^{\circ} \mathrm{C}$ respectivement) et une phase de refroidissement. La formulation adimensionnelle développée dans la procédure permet d'utiliser des éléments de Kelvin activés thermiquement même lorsque les tests ne sont pas isothermes. Pour chaque essence et chaque direction, les quatre essais de fluage sont analysés conjointement pour définir les paramètres du modèle de comportement. L'article se termine par une caractérisation complète du chêne et de l'épicéa en directions radiale et tangentielle, sur une plage de température de $40^{\circ} \mathrm{C}$ à $120^{\circ} \mathrm{C}$. Cinq éléments de Kelvin sont nécessaires pour l'épicéa, quatre pour le chêne. Ces modèles peuvent être utilisés pour la simulation d'opération de transformation du bois, tels que le séchage, l'étuvage ou le traitement thermique.

bois / viscoélastique / élément de Kelvin / activation thermique / modèle de comportement / méthode inverse

\section{INTRODUCTION}

This two-part paper proposes a comprehensive study of viscoelastic behaviour of green wood in the transverse plane (radial and tangential directions) over a large temperature range extending from room temperature to $120^{\circ} \mathrm{C}$. The experimental set-up able to perform creep tests above the boiling point of water was described in the first part of this paper. The latter also includes a full presentation of a complete set of bending creep tests at different temperature values for Spruce (Picea abies) and Oak (Quercus). The present part is devoted to the analysis of this set of data in order to propose a viscoelastic model and the corresponding parameters to be used in engineering processes, such as steaming, forming, drying at low and high temperature...
Numerous works have been devoted to constitutive models of solid materials having memory effects. In this work, the evolution of creep versus time or temperature is supposed to result from a viscoelastic behaviour, which is completely defined once the creep function, a fourth order tensorial function, is defined [4, 12]. Creep tests performed with sudden load at initial time and constant parameters (temperature and moisture content) are well adapted to the determination of scalar components of this tensorial creep function. Indeed, in this case, the convolution product, which allows the sample response to be determined at any time, becomes straightforward. Although these components are usually decreasing functions, more general shapes have been proposed to account for specific mechanisms [7]. Exponential and power functions are two possible functions usually adopted for wood. The first family is widespread

\footnotetext{
* Corresponding author: perre@engref.fr
} 
because each exponential function can be mechanically interpreted as the response of a Kelvin's element (a dashpot and a spring placed in parallel). In addition, these functions are easy to be implemented in computational code, because the entire material history can be embodied in internal variables whose evolution obeys simple differential equations. However, parabolic elements have been proposed because they allow the experimental points plotted in the Cole-Cole representation (loss modulus as a function of storage module) to be fitted with very few elements, typically one per transition, when wood is analysed as a multitransition mixture of macromolecules $[8,11]$.

Although a kind of equivalence can be found between parabolic and Kelvin's elements [1], one has to keep in mind that the number of parameters that may be identified from experimental data is limited by the quality and the parameter domain of the available data. The natural variability of wood induces a scattering of experimental values, especially when several tests with different samples have to be analysed simultaneously. Furthermore, the physical principles and technical specifications of any apparatus limit the possible range of parameter evolution (time, temperature, moisture content).

The strategy adopted in this work is pragmatic: our goal is to propose an operative model for the viscoelastic behaviour of green wood valid over a wide range of temperature levels and for time constants representative of industrial processes involving heat and mass transfer.

As explained previously the choice of Kelvin's elements placed in series insures a simple implementation in numerical codes. In addition, each element has its own activation energy and retardation time at $20^{\circ} \mathrm{C}$ : this important feature has allowed the large temperature range (from room temperature up to $120^{\circ} \mathrm{C}$ ) to be properly described with 5 elements only (15 fitting parameters), which is rather low compared to similar works [6]. Following this choice, the pathway in the Cole-Cole diagram is not unique, but depends on the temperature level. This failure of the time-temperature equivalence is not proved in the present work; this is just a consequence of our choice. However, this result is consistent with a refined observation of some experimental or theoretical works $[1,11]$.

In order to identify all parameters required to define the Kelvin's elements, a new inverse method has been implemented in Fortran 90. It uses the theoretical solution of a cantilever beam submitted to constant load and variable temperature. From this solution, the objective function to be minimised is the mean square discrepancy between the experimental measurements and the calculated solutions. In the latter, the actual sample temperature measured during the creep test by a thermocouple implemented in the sample, is used as input parameter in the theoretical solution to calculate the deflection. In addition, our new procedure is able to deal with several tests simultaneously, which was not possible in a former work [16]. For this purpose, a specific dimensionless formulation has been derived, which allows different samples to be compared. This specificity dramatically improves the performance of the inverse method, hence the potential of the resulting constitutive equation. Indeed, by using tests carried out at different temperature levels, the final solution is very robust and valuable over the entire range of temperature levels.

\section{THE THEORETICAL FORMULATION}

\subsection{Thermally activated Kelvin's elements}

Although wood is strongly anisotropic, a 1-D formulation will be used in this section. This assumption implies that only one creep function of the tensorial constitutive equation will be defined from a series of tests. In particular, the shear strain is neglected (this assumption has been justified in part I of this paper) and the procedure only applies to samples cut along the material directions of wood. Several formulations have been proposed in the literature to fit experimental creep functions obtained for wood. For example, Huet [8] has proposed parabolic elements. However, although efficient to fit experimental data, they required a very complex treatment when using the constitutive equation in computational models. For this practical reason, the behaviour of the material is often analysed as N Kelvin elements associated in series $[5,6,9,10]$. From this choice results the following creep function:

$$
J(t)=a_{0}+\sum_{n=1}^{N} a_{n}\left[1-\exp \left(\frac{-t}{\tau_{n}}\right)\right] .
$$

The temperature and moisture dependency of that function can be expressed using a material time or changing the characteristic time $\tau_{n}$. The thermal activation, for example, is often expressed with the aid of an Arrhenius law:

$$
\tau_{n}=\tau_{n}^{\infty} \exp \left(+\frac{\Delta W_{n}}{R T}\right) .
$$

$\Delta W_{n}$ is the activation energy associated to element $n\left(\mathrm{~J} \cdot \mathrm{mol}^{-1}\right) ; R$ is the constant of ideal gases $\left(8,314 \mathrm{~J} \cdot \mathrm{K}^{-1} \cdot \mathrm{mol}^{-1}\right) ; T$ is the absolute temperature $(\mathrm{K}) ; \tau_{n}^{\infty}$ is the retardation time for an "infinite" temperature.

$\tau_{n}^{\infty}$ has no simple meaning. In the present work, $\tau_{n}^{20}$, the retardation time at $20^{\circ} \mathrm{C}$ will be computed from the other parameters using the following expression:

$$
\tau_{n}^{20}=\tau_{n}^{\infty} \exp \left(\frac{\Delta W_{n}}{R \times 293}\right) .
$$

Equation (1) is the expression that was used in a previous work [16]. Nevertheless, in the present work, we have to analyse at the same time different tests carried out on different samples. Indeed, in order to be able to treat simultaneously different temperature-time itineraries, different samples have to be used. This implies that we have to face the natural variability of wood. Based on several experimental data, we observed that the viscoelastic properties of wood is almost proportional to its elastic behaviour, provided we use the same species and the same material direction [14]. All data obtained in the experimental procedure described in part I of this paper depict the same trend. For example, Figure 1 reports three experiments carried out on different Spruce samples using the same time-temperature itinerary (temperature plateau equal to $85^{\circ} \mathrm{C}$ ). On this graph, it becomes obvious that the gap between the corresponding curves, plotted in a semi-log graph, remains almost constant throughout the test. This constant gap proves that similar samples keep the same ratio for the apparent modulus. The following expression, which relies on these observations, will be used throughout the paper. In this expression, the $\mathrm{N}$ parameters $a_{n}^{*}$ are dimensionless factors:

$$
J(t)=a_{0}\left\{1+\sum_{n=1}^{N} a_{n}^{*}\left[1-\exp \left(\frac{-t}{\tau_{n}}\right)\right]\right\}
$$

where $a_{n}^{*}=a_{n} / a_{0}$.

In equation (4), the value of $a_{0}$ comes from the elastic test done on the sample at room temperature just before the creep test [15]. 


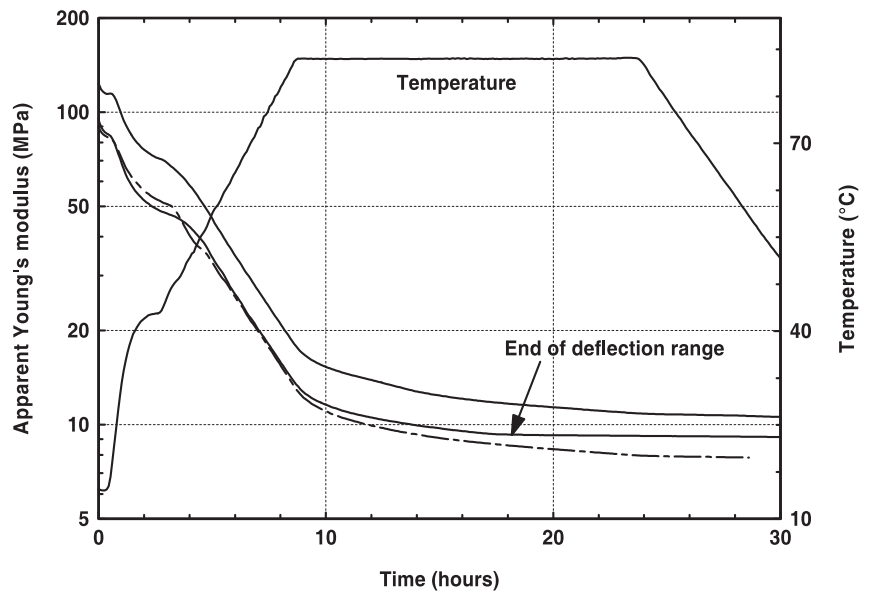

Figure 1. Three experiments carried out on different Spruce samples in radial direction using the same time-temperature itinerary $\left(85^{\circ} \mathrm{C}\right)$. The gap between the curves remains almost constant, in the Log scale, which proves that similar samples keep the same ratio for the apparent modulus.

In summary, by using equation (4) instead of equation (1), different samples tested at different temperature levels can be compared and used simultaneously to fit the parameters of the constitutive model. In this possibility lies the main innovation of the inverse method proposed here. This feature is the key element of the identification procedure and guarantees the quality of the fitted parameters and the wide range of validity of the resulting constitutive model.

\subsection{Simulation of the experimental tests}

The creep function applies directly when a constant load is applied from time $t=0$ in isothermal conditions. Due to this simplicity, these tests are generally used to characterise the creep function. In such cases, the relationship between the viscoelastic creep strain $\varepsilon(t)$ and the stress level $\sigma$ is straightforward:

$$
\varepsilon_{t o t}(t)=\sigma a_{0}\left\{1+\sum_{n=1}^{N} a_{n}^{*}\left[1-\exp \left(\frac{-t}{\tau_{n}}\right)\right]\right\} \text {. }
$$

However, when the material has to be tested at high temperature levels and particularly when the experiment has to be carried under pressure, it becomes very difficult to start with the desired temperature level. Instead, the load is applied first and the temperature increases during the creep test. In such tests, formula (5) is not valid anymore. The creep strain has to be computed as the integrative of the deformation rate:

with

$$
\begin{gathered}
\frac{\mathrm{d} \varepsilon_{t o t}}{\mathrm{~d} t}=\sum_{n} \frac{\mathrm{d} \varepsilon_{n}}{\mathrm{~d} t} \\
\frac{\mathrm{d} \varepsilon_{n}}{\mathrm{~d} t}=\sigma a_{0}\left(a_{n}^{*}-\varepsilon_{n}\right) \frac{1}{\tau_{n}(T)} .
\end{gathered}
$$

In practice, the total creep strain is computed from successive finite time increments $\delta t$, assuming that the time constant $\tau_{n}$ remains constant over this time increment. However, because the time constant dramatically varies versus the temperature level or from one Kelvin's element to the other, an exact integration of the exponential function, rather than a first order approximation, is used in our simulations:

$$
\begin{gathered}
\delta \varepsilon_{\text {tot }}=\sum_{n} \delta \varepsilon_{n} \\
\delta \varepsilon_{n}=\left(\sigma a_{0} a_{n}^{*}-\varepsilon_{n}\right)\left\{1-\exp \left(\frac{-\delta t}{\tau_{n}(T)}\right)\right\} .
\end{gathered}
$$

Assuming the viscoelastic behaviour of wood to be linear, expression (7) allows the deflection of any cantilever beam to be computed versus time with the aid of any estimated set of elements parameters. This calculation simply uses the expression obtained in elasticity for a cantilever beam and the actual temperature and load of the beam at each time. In this procedure, the deflection is computed from the dimensionless parameters $a_{n}^{*}$ and the value of the Young modulus of the corresponding samples, as determined at room temperature $\left(a_{0}=1 / E\right)$. In order to calculate the deflexion $\mathrm{H}(t)$ at time $t$, it is useful to introduce the apparent modulus of elasticity $E_{a p p}(t)$ at the same time $t$. The latter involves the entire history of the sample:

$$
E_{a p p}(t)=\frac{\sigma(t)}{\int_{0}^{t} \sum_{n}\left\{\left(\sigma(t) a_{0} a_{n}^{*}-\varepsilon_{n}(t)\right) \frac{1}{\tau_{n}(T(t))}\right\} \mathrm{d} t} .
$$

Because the strain rate and the memory strain in equation (6) depends linearly on the stress value $\sigma$, the apparent modulus of elasticity calculated by equation (8) does not depend on the stress level, provided that its evolution versus time is the same for all parts of the section. This hypothesis is reasonable here because the temperature field can be assumed to be constant (the thermal time constant of the sample is small compared to the heating rate) and because our experimental protocol insures that no shrinkage exists in the sample. By neglecting the deflexion due to shear strain [15], one simply obtains:

$$
H(t)=\frac{6 P L_{0}^{2} L}{{ }_{{ }_{0}} h^{3} E_{a p p}(t)} .
$$

\subsection{The inverse method used to define the model parameters}

Once the constitutive equation has been chosen, the parameters of this equation must be obtained from the experimental data. This procedure, called inverse method, requires an objective function $f$ to be determined and a relevant algorithm to be used to minimise its value. The objective function chosen in the present work estimated the average distance, over several tests, between the experimental and the simulated curves in the sense of the mean square values:

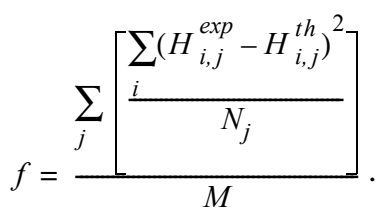

$H_{i, j}^{e x p}$ is the experimental deflection of test $j$ at discrete time $i ; H_{i, j}^{t h}$ is the deflection computed for test $j$ at discrete time $i$ using the estimated set of parameters; $N_{j}$ is the number of discrete time for test $j$; $M$ is the number of tests used to identify the parameters of the constitutive model.

Keeping in mind that each Kelvin's element produces three independent parameters $\left(a_{n}^{*}, \tau_{n}^{\infty}\right.$ et $\left.\Delta W_{n}\right)$, it becomes evident that the inverse method algorithm should be able to deal with multidimensional minimisation. In addition, Kelvin's elements with thermal activation involve dramatic non-linear behaviour. The downhill simplex 

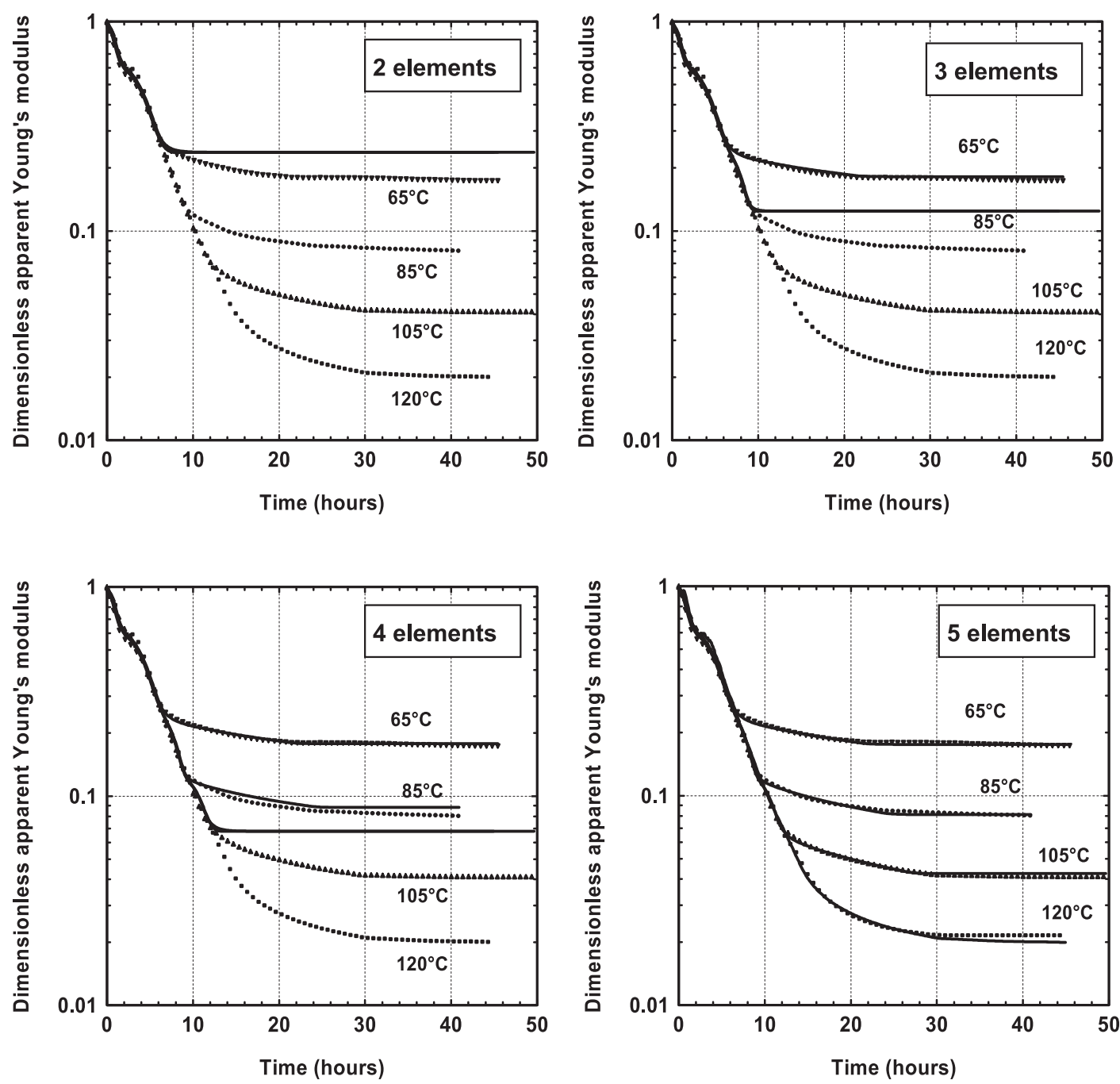

Figure 2. Contribution of the different Kelvin's elements when simulating tests carried out at different temperature levels $\left(65^{\circ} \mathrm{C}, 85^{\circ} \mathrm{C}, 105^{\circ} \mathrm{C}\right.$ and $120^{\circ} \mathrm{C}$ ). Case of Spruce, tangential direction.

algorithm is used in this work [18]. This method requires only function evaluation, not derivatives. Although not especially efficient in terms of the number of function evaluations, this method is quite effective in avoiding local minima, namely by using a large initial simplex. In $\mathrm{N}$ dimensions, the simplex consists of $\mathrm{N}+1$ vertices. If the simplex is non-degenerated, any point connected to each of the other points defines vector directions able to span the $\mathrm{N}$-dimensional vector space. From the initial simplex and the values of the objective function at each vertex, the downhill simplex algorithm changes the shape of the simplex by basic moves (reflection, reflection and expansion, contraction, multiple contraction...). Once convergence is obtained, the simplex contracts into a very small size around the "floor valley".

At this point, one has to stress the reader on the numerous traps that might be encountered in multidimensional minimisation of a highly non-linear objective function. In order to face this critical problem, a windows-like application has been developed in Fortran 95 using a set of graphical functions (Winteracter provided by Interactive Software Services). This application, which embodies more than 2000 lines, allows the user to load any set of experimental tests and to plot the experimental and simulated curves. In order to avoid negative param- eters, hence a non-physical solution, without breaking the minimisation algorithm, each parameter is sought as the exponential value of a real number. Moreover, the number of Kelvin's elements, the active experimental curves and the region of interest for each curve can be chosen and modified during the optimisation procedure. Once done, we always start the minimisation again, using a large simplex around the solution, just to be sure not to be trapped into a local minimum.

For the resulting set of parameters to keep a physical meaning, we start the minimisation procedure with the test carried out at the lowest temperature level and try to get a good fit with a minimum number of Kelvin's elements. Then, we progressively load additional tests, done at increasing temperature levels and add Kelvin's elements if required. For the sake of argument, Figure 2 depicts the results obtained for Spruce in the tangential direction. It is clear from these graphs that two elements are just enough to simulate the first increase in temperature up to about $60{ }^{\circ} \mathrm{C}$. The third element produces a perfect simulated curve for the test carried out at $65^{\circ} \mathrm{C}$, including the plateau at constant temperature, but is just able to restituate the initial increase in temperature for the test at $85^{\circ} \mathrm{C}$. Similarly, the fourth element approaches quite well the plateau at $85^{\circ} \mathrm{C}$ and can capture the increase in temperature 
Table I. Parameter values of the five Kelvin's elements fitted for Spruce in tangential direction. The average modulus of elasticity $\left(1 / \mathrm{a}_{0}\right)$ is equal to $133 \mathrm{MPa}$.

\begin{tabular}{cccc}
\hline$n$ & $\begin{array}{c}\text { Dimensionless delayed } \\
\text { modulus }\left(1 / a_{n}^{*}\right)\end{array}$ & $\begin{array}{c}\text { Retardation time } \\
\text { at } 20{ }^{\circ} \mathrm{C} \tau_{n}^{20} \text { (hours) }\end{array}$ & $\begin{array}{c}\text { Activation energy } \\
\mathrm{kJ} / \mathrm{mole}\end{array}$ \\
\hline 1 & 1.77 & 1.89 & 62.3 \\
2 & 0.38 & 414 & 109.2 \\
3 & 0.26 & $8.83 \times 10^{+6}$ & 221.9 \\
4 & 0.14 & $3.68 \times 10^{+7}$ & 190.0 \\
5 & 0.029 & $1.75 \times 10^{+7}$ & 137.3 \\
\hline
\end{tabular}

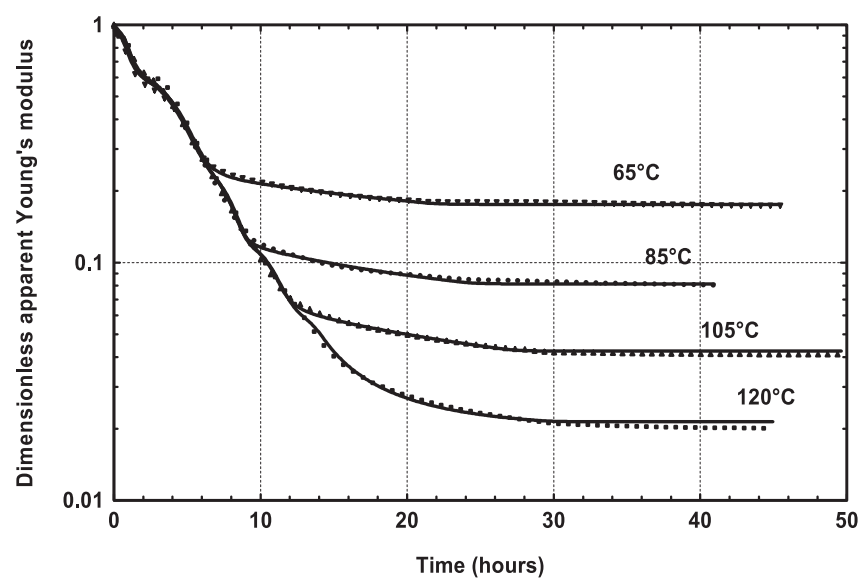

Figure 3. Creep tests in the tangential direction of Spruce. Evolution of the experimental apparent modulus of elasticity determined at four different temperature levels $\left(65^{\circ} \mathrm{C}, 85^{\circ} \mathrm{C}, 105^{\circ} \mathrm{C}\right.$ and $\left.120^{\circ} \mathrm{C}\right)$ and the corresponding simulated results obtained using the five Kelvin's elements defined in Table I.

up to $105^{\circ} \mathrm{C}$. Finally, it has to be noticed that the fifth element is very efficient: it allows the plateau at $105^{\circ} \mathrm{C}$, the increase up to $120^{\circ} \mathrm{C}$ and the plateau at $120^{\circ} \mathrm{C}$ to be perfectly caught.

This general trend was observed in both material directions for Spruce we always ended up with five different Kelvin's elements for this species. However, the fourth element was able to fit the two remaining tests $\left(105^{\circ} \mathrm{C}\right.$ and $\left.120^{\circ} \mathrm{C}\right)$ in the case of Oak. This is why four elements are proposed in this work for this species.

\section{RESULTS}

\subsection{Spruce}

Table I and Figure 3 summarise the fitted results obtained for Spruce in the tangential direction. According to our identification procedure, the numbering of the Kelvin's elements has a sense: from number 1 to number 5, one can observe that the delayed Young's modulus decreases and that the retardation time increases. Indeed, we progressively shift from elements having a low softening potential but acting at a relatively low temperature level towards elements with a high softening potential which requires a high temperature level to manifest.
Table II. Parameter values of the five Kelvin's elements fitted for Spruce in radial direction. The average modulus of elasticity $\left(1 / \mathrm{a}_{0}\right)$ is equal to $237 \mathrm{MPa}$.

\begin{tabular}{cccc}
\hline$n$ & $\begin{array}{c}\text { Dimensionless delayed } \\
\text { modulus }\left(1 / a_{n}^{*}\right)\end{array}$ & $\begin{array}{c}\text { Retardation time } \\
\text { at } 20{ }^{\circ} \mathrm{C} \tau_{n}^{20} \text { (hours) }\end{array}$ & $\begin{array}{c}\text { Activation energy } \\
\mathrm{kJ} / \mathrm{mole}\end{array}$ \\
\hline 1 & 1.69 & 1.77 & 56.7 \\
2 & 0.45 & 501 & 109.6 \\
3 & 0.37 & $3.21 \times 10^{+7}$ & 237.6 \\
4 & 0.23 & $4.65 \times 10^{+6}$ & 167.5 \\
5 & 0.027 & $2.93 \times 10^{+7}$ & 136.5 \\
\hline
\end{tabular}

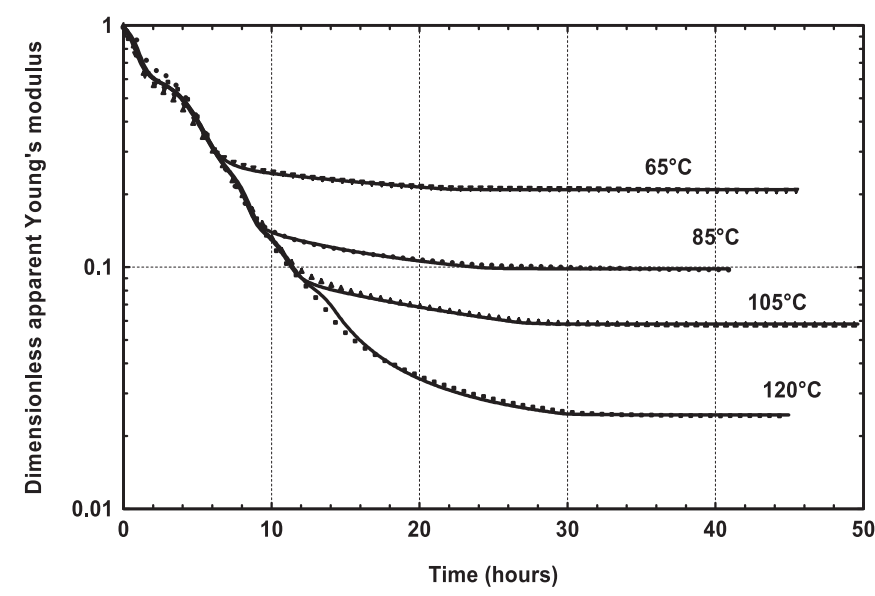

Figure 4. Creep tests in the radial direction of Spruce. Evolution of the experimental apparent modulus of elasticity determined at four different temperature levels $\left(65^{\circ} \mathrm{C}, 85^{\circ} \mathrm{C}, 105^{\circ} \mathrm{C}\right.$ and $\left.120^{\circ} \mathrm{C}\right)$ and the corresponding simulated results obtained using the five Kelvin's elements defined in Table II.

Thanks to our dimensionless analysis, the parameter values obtained for Spruce in the radial direction are very similar (Tab. II). Indeed, these results confirm that the anisotropy ratio of Spruce in the transverse plane is very little affected by thermal activation [14]. As for tangential direction, the fitted curves are very close to the experimental curves (Fig. 4): whatever the direction, one can conclude that five thermo-activated Kelvin's elements are enough to obtained a very nice set of simulated curves. One has to notice that this excellent result is due to the choice of independent parameters for all Kelvin's element, namely the retardation time and the activation energy. One has also to keep in mind that this choice breaks the time-temperature equivalence.

\subsection{Oak}

In the case of Oak, the curves obtained for different samples present some discrepancy, namely during the first increase in temperature up to $70{ }^{\circ} \mathrm{C}-80^{\circ} \mathrm{C}$. As explained in [15] this is probably due to the recovery of growth stresses, especially in samples containing tension wood. For this reason, we removed some parts of certain curves in the minimisation procedure for 


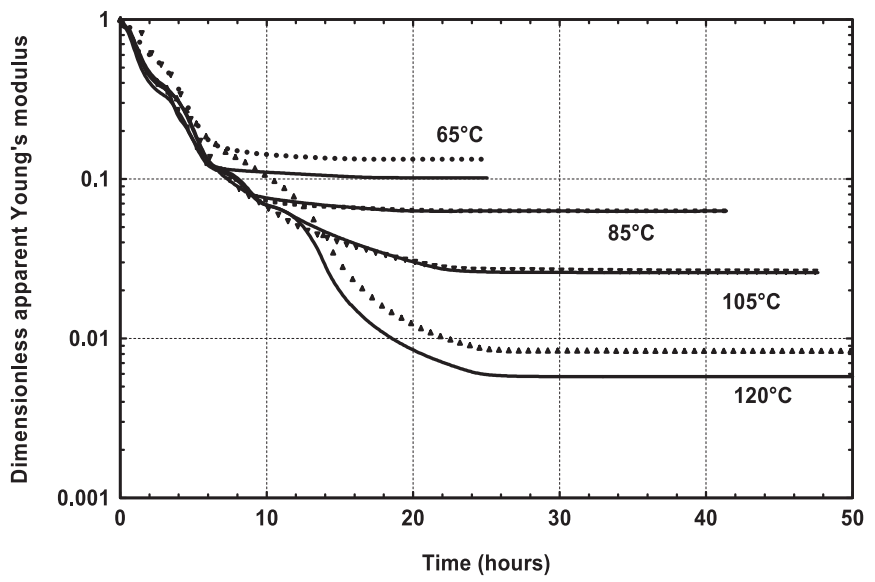

Figure 5. Creep tests in the tangential direction of Oak. Evolution of the experimental apparent modulus of elasticity determined at four different temperature levels $\left(65^{\circ} \mathrm{C}, 85^{\circ} \mathrm{C}, 105^{\circ} \mathrm{C}\right.$ and $\left.120^{\circ} \mathrm{C}\right)$ and the corresponding simulated results obtained using the four Kelvin's elements defined in Table III.

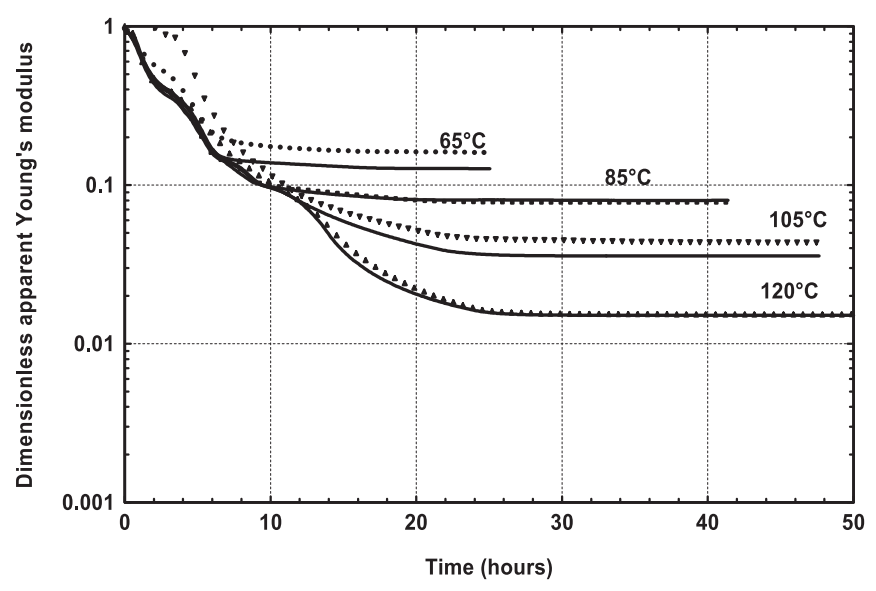

Figure 6. Creep tests in the radial direction of Oak. Evolution of the experimental apparent modulus of elasticity determined at four different temperature levels $\left(65^{\circ} \mathrm{C}, 85^{\circ} \mathrm{C}, 105^{\circ} \mathrm{C}\right.$ and $\left.120^{\circ} \mathrm{C}\right)$ and the corresponding simulated results obtained using the four Kelvin's elements defined in Table IV.

Oak and we accepted some variations (up to 10\%) in the modulus of elasticity put in the identification procedure compared to the value determined at room temperature. This variation explains the discrepancy between experiment and simulation at the end of certain tests (Figs. 5 and 6). Because Oak, a hardwood species, presents a marked softening region in the range $70{ }^{\circ} \mathrm{C}-85^{\circ} \mathrm{C}$ when saturated, three Kelvin's elements are necessary to reproduce the experimental behaviour up to $85^{\circ} \mathrm{C}$. Surprisingly, one single element proved to be enough to fit the behaviour of all remaining tests at higher temperature levels, including the $10 \mathrm{~h}$ long plateau at constant temperature.

The parameter identification depicts a similar behaviour in radial and tangential directions. At first sight, the fitted parameter seems to be quite different in radial and tangential direc-
Table III. Parameter values of the four Kelvin's elements fitted for Oak in tangential direction. The average modulus of elasticity $\left(1 / \mathrm{a}_{0}\right)$ is equal to $413 \mathrm{MPa}$.

\begin{tabular}{cccc}
\hline$n$ & $\begin{array}{c}\text { Dimensionless delayed } \\
\text { modulus }\left(1 / a_{n}^{*}\right)\end{array}$ & $\begin{array}{c}\text { Retardation time } \\
\text { at } 20^{\circ} \mathrm{C} \tau_{n}^{20} \text { (hours) }\end{array}$ & $\begin{array}{c}\text { Activation energy } \\
\mathrm{kJ} / \mathrm{mole}\end{array}$ \\
\hline 1 & 0.701 & 3.68 & 36.38 \\
2 & 0.165 & 4757 & 100.7 \\
3 & 0.181 & $2.88 \times 10^{+6}$ & 200.4 \\
4 & $2.65 .10^{-3}$ & $1.54 \times 10^{+8}$ & 149.5 \\
\hline
\end{tabular}

Table IV. Parameter values of the four Kelvin's elements fitted for Oak in radial direction. The average modulus of elasticity $\left(1 / \mathrm{a}_{0}\right)$ is equal to $729 \mathrm{MPa}$.

\begin{tabular}{cccc}
\hline$n$ & $\begin{array}{c}\text { Dimensionless delayed } \\
\text { modulus }\left(1 / a_{n}^{*}\right)\end{array}$ & $\begin{array}{c}\text { Retardation time } \\
\text { at } 20{ }^{\circ} \mathrm{C} \tau_{n}^{20} \text { (hours) }\end{array}$ & $\begin{array}{c}\text { Activation energy } \\
\mathrm{kJ} / \mathrm{mole}\end{array}$ \\
\hline 1 & 0.626 & 3.55 & 38.89 \\
2 & 0.239 & 6307 & 168.3 \\
3 & 0.369 & $7.49 \times 10^{+6}$ & 218.2 \\
4 & $1.14 .10^{-2}$ & $8.42 \times 10^{+5}$ & 103.9 \\
\hline
\end{tabular}

tions for elements 2 to 4 (Tabs. III and IV). However, the cumulative effects of the retardation time and the activation energy has to be well understood. Both parameters define the temperature over which this element acts: the median temperature and the spread of the zone. By increasing both the retardation time and the activation energy, one can obtain the same median temperature with a reduced spread. Such an effect does not change dramatically the overall shape of the curve. Therefore, even so the trend is stable, the value of one single parameter may depend strongly on the experimental data.

\section{DISCUSSION}

The Cole-Cole plot is a convenient way to summarise the resulting viscoelastic behaviour. These plots have been computed using the model parameters defined by the inverse method. Figures 7 and 8 depict the Cole-Cole plots obtained for Spruce and Oak, respectively, in radial and tangential directions, for three temperature values. The frequency range used to build these plots ranges from $3 \cdot 10^{-5}$ to $1.5 \cdot 10^{-2} \mathrm{~Hz}$, which corresponds to a time constant stretching from $1 \mathrm{~min}$ to $10 \mathrm{~h}$. This range of time is representative of most processes involving heat and mass transfer (drying, forming, steaming).

One can notice that for the same species, the shape of the Cole-Cole plot is very similar in tangential and radial directions. On the contrary, the difference between softwood and hardwood is obvious. The glass transition of softening temperature for wood depends on the physical method used and the constant of time. Nevertheless, differences between softwood and hardwood have been reported in the literature [2, 5, 13]. This is certainly due to the difference in lignin compositions between softwood and hardwoods: almost only guaiacyl units are present in softwoods and a mixture of guaiacyl and syringyl 

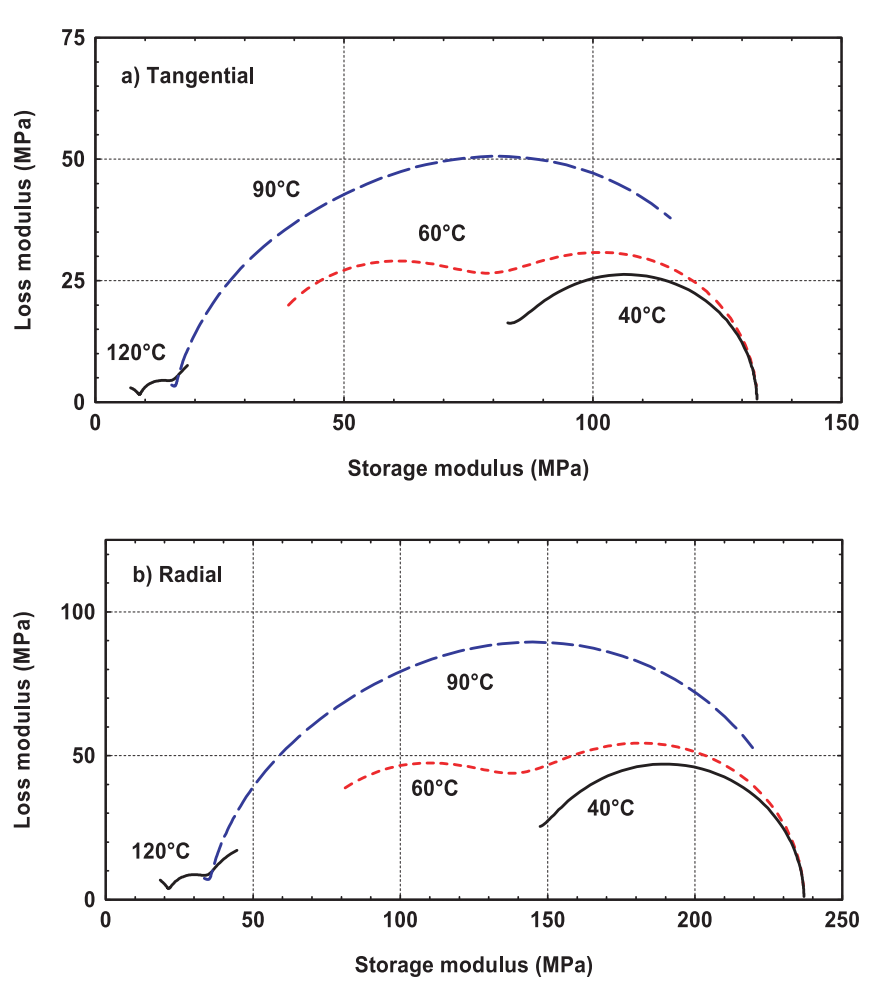

Figure 7. The Cole-Cole plots obtained with the Kelvin's elements for Spruce in the tangential (a) and radial (b) directions at four different temperature level $\left(40{ }^{\circ} \mathrm{C}, 60^{\circ} \mathrm{C}, 90^{\circ} \mathrm{C}\right.$ and $\left.120^{\circ} \mathrm{C}\right)$. The frequency range used to build these plots ranges from $3 \times 10^{-5}$ to $1.5 \times 10^{-2} \mathrm{~Hz}$. This range corresponds to a time period stretching from $1 \mathrm{~min}$ to $10 \mathrm{~h}$, which is representative of most processes involving heat and mass transfer.

units in hardwoods. The effect of the ratio was clearly assessed by Olsson and Salmén [13]. Note that syringyl units in hardwoods are present mainly in the secondary wall [3], which tends to prove that the cell wall, rather than the middle lamella is responsible for this difference of behavior between softwood and hardwood.

\section{CONCLUSION}

This two-part paper proposed four main aspects:

- an enhanced experimental device able to perform creep tests on green wood up to $120^{\circ} \mathrm{C}$;

- an analysis of the raw data obtained from several tests on oak and spruce;

- a new inverse method to identify Kelvin's elements simultaneously from several tests;

- a comprehensive viscoelastic characterisation of oak and spruce in radial and tangential directions, over a temperature range spreading from $40^{\circ} \mathrm{C}$ to $120^{\circ} \mathrm{C}$.

The results obtained by this experimental and numerical method can be used for prediction purposes, provided the temperature and time ranges are in agreement with the experimental windows used in this work (typically $40{ }^{\circ} \mathrm{C}$ to $120^{\circ} \mathrm{C}$ and some seconds to some hours). In particular, all processing oper-
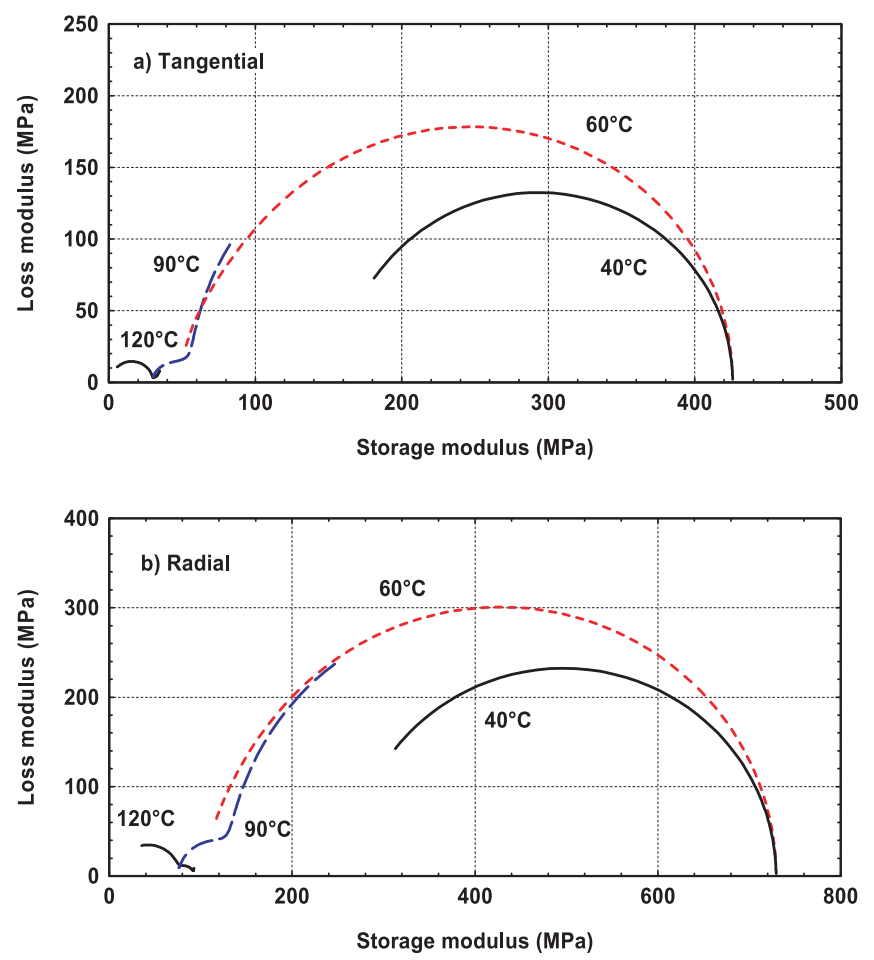

Figure 8. The Cole-Cole plots obtained with the Kelvin's elements for Oak in the tangential (a) and radial (b) directions at four different temperature level $\left(40^{\circ} \mathrm{C}, 60{ }^{\circ} \mathrm{C}, 90^{\circ} \mathrm{C}\right.$ and $\left.120^{\circ} \mathrm{C}\right)$. The frequency range used to build these plots ranges from $3 \times 10^{-5}$ to $1.5 \times 10^{-2} \mathrm{~Hz}$. This range corresponds to a time period stretching from $1 \mathrm{~min}$ to $10 \mathrm{~h}$, which is representative of most processes involving heat and mass transfer.

ations that involve heat and mass transfer may be concerned. For example, the Kelvin's elements parameters have already been tested successfully to simulate drying stresses [17].

On the other hand, some problems appeared when using creep tests at increasing temperature. The most important ones concern the growth stresses recovery by thermal activation and the possible thermal degradation that might occur during the creep test, especially at $105^{\circ} \mathrm{C}$ and $120^{\circ} \mathrm{C}$. In order to address these problems, a new experimental device able to perform harmonic tests in the same conditions is under construction in our laboratory.

\section{REFERENCES}

[1] Bardet S., Gril J., Modelling the transverse viscoelasticity of green wood using a combination of two parabolic elements, C. R. Mécanique 330 (2002) 549-556.

[2] Bardet S., Beauchêne J., Thibaut B., Influence of basic density and temperature on mechanical properties perpendicular to grain of ten wood tropical species, Ann. For. Sci. 60 (2003) 49-59.

[3] Donaldson L.A., Lignification and lignin topochemistry: an ultrastructural view, Phytochemistry 57 (2001) 859-873.

[4] Findley W.N., Lai J.S., Onaran K., Creep and relaxation of nonlinear viscoelastic materials, North-Holland Pub. Company, 1976. 
[5] Genevaux J.-M., Le fluage à température linéairement croissante : Caractérisation des sources de viscoélasticité anisotrope du bois, Thèse de Doctorat de l'Institut National Polytechnique de Lorraine, Nancy, France, 1989.

[6] Hanhijärvi A., Deformation properties of Finnish spruce and pine wood in tangential and radial directions in association to high temperature drying. Part II. Experimental results under constant conditions (viscoelastic creep), Holz als Roh- Werkst. 57 (1999) 365372.

[7] Hazanov S., A new class of creep-relaxation functions, Int. J. Solids Struct. 32 (1995) 165-172.

[8] Huet C., Some aspects of the thermo-hygro-viscoelastic behaviour of wood, in: Morlier P. (Ed.), Mechanical Behaviour of Wood, Bordeaux, 1988, pp. 104-118.

[9] Martensson A., Mechanical behaviour of wood exposed to humidity variations, Doctoral dissertation, Lund Institute of Technology, Sweden, 1992.

[10] Mohager S., Toratti T., Long term bending creep of wood in cyclic relative humidity, Wood Sci. Technol. 27 (1993) 49-59.

[11] Nakano T., Time-temperature superposition principle on relaxational behaviour of wood as a multi-phase material, Holz RohWerkst. 53 (1995) 39-42.
[12] Ogden R.W., Non-linear elastic deformation, Dover Publication, New York, USA, 1997.

[13] Olsson A.-M., Salmén L., Viscoelasticity of in situ lignin as affected by structure, softwood vs. hardwood, ACS Symposium Series No. 489, American Chemical Society, 1992, pp. 133-143.

[14] Passard J., Perré P., Creep tests under water-saturated conditions: do the anisotropy ratios of wood change with the temperature and time dependency? 7th International IUFRO Wood Drying Conference, Tsukuba, Japan, 2001, pp. 230-237.

[15] Passard J., Perré P., Viscoelastic behaviour of green wood across the grain. Part I. Thermally activated creep tests up to $120^{\circ} \mathrm{C}$, Ann. For. Sci. 62 (2005) 707-716.

[16] Perré P., Aguiar O., Fluage du bois "vert" à haute température $\left(120^{\circ} \mathrm{C}\right)$ : expérimentation et modélisation à l'aide d'éléments de Kelvin thermo-activés, Ann. For. Sci. 56 (1999) 403-416.

[17] Perré P., Passard J., A physical and mechanical model able to predict the stress field in wood over a wide range of drying conditions, Dry. Technol. 22 (2004) 27-44.

[18] Press W.H., Teukolsky S.A., Vetterling W.T., Flannery B.P., Numerical Recipes in Fortran, The Art of Scientific Computing, Cambridge University Press, 2nd ed., 1992, pp. 402-406. 